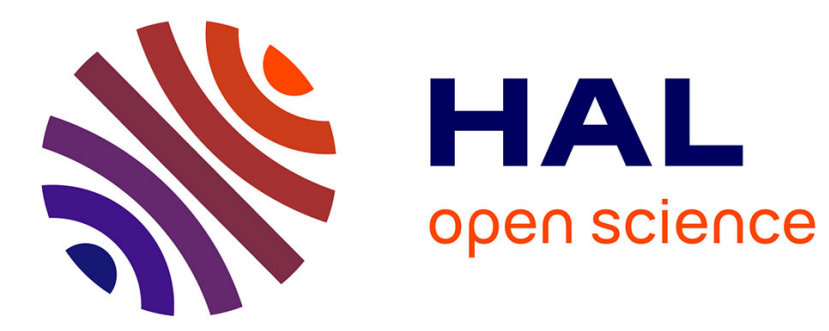

\title{
Time-resolved study of thymine dimer formation
}

\author{
Sylvie Marguet, Dimitra Markovitsi
}

\section{To cite this version:}

Sylvie Marguet, Dimitra Markovitsi. Time-resolved study of thymine dimer formation. Journal of the American Chemical Society, 2005, 127, pp.5780-5781. 10.1021/ja050648h . hal-00083445

\section{HAL Id: hal-00083445 https://hal.science/hal-00083445}

Submitted on 30 Jun 2006

HAL is a multi-disciplinary open access archive for the deposit and dissemination of scientific research documents, whether they are published or not. The documents may come from teaching and research institutions in France or abroad, or from public or private research centers.
L'archive ouverte pluridisciplinaire HAL, est destinée au dépôt et à la diffusion de documents scientifiques de niveau recherche, publiés ou non, émanant des établissements d'enseignement et de recherche français ou étrangers, des laboratoires publics ou privés. 


\section{Time-Resolved Study of Thymine Dimer Formation \\ Sylvie Marguet and Dimitra Markovitsi* \\ Laboratoire Francis Perrin CEA/DSM/DRECAM/SPAM - CNRS URA 2453, CEA Saclay, 91191 Gif-sur-Yvette, France}

\section{RECEIVED DATE (automatically inserted by publisher); Dimitra.Markovitsi@cea.fr}

Absorption of UV radiation by DNA bases induces mutations which appear mainly at bipyrymidine sites. ${ }^{1,2}$ The major photoproducts are cyclobutane dimers and pyrimidine-(6-4)pyrimidone adducts. The latter are considered to result via oxetane or azedine intermediates which undergo ring opening.

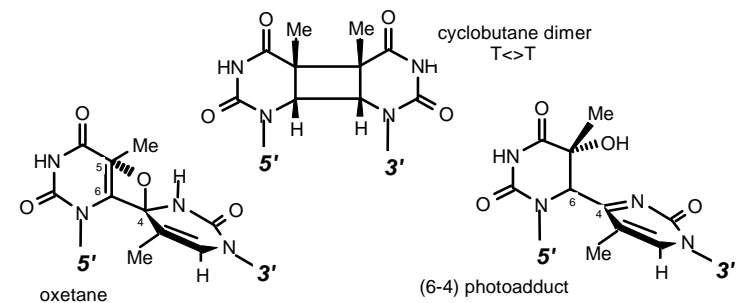

Figure 1 Structure of the dimeric thymine photoproducts.

Since the isolation of the first bipyrimidine dimers, ${ }^{3-5}$ a large number of studies aiming at the understanding of the various factors which play a role in their formation have been published. ${ }^{6}$ In spite of the intense work in this field, there is still complete lack of information regarding the time-scales at which cyclobutane dimers and (6-4) adducts are formed. Laser flash photolysis experiments, which provide such information, are difficult to perform for DNA components. Indeed, data are distorted by excitation of accumulated photoproducts. Moreover, hydrated electrons and radical ions resulting from two photon ionization ${ }^{7}$ obscure absorption related to other processes occurring with low quantum yield. In the present laser flash photolysis investigation, dedicated to the single stranded oligonucleotide $(\mathrm{dT})_{20}$, we managed to overcome the above difficulties. We used continuous flow of the solutions and low excitation densities $\left(\leq 1.2 \mathrm{MW} / \mathrm{cm}^{2}\right)$ to avoid ionization of the studied systems. We show that direct excitation of the oligonucleotide leads to cyclobutane dimers $(\mathrm{T}<>\mathrm{T})$ in less than 200 ns whereas the (6-4) adduct is formed within $4 \mathrm{~ms}$ via a reaction intermediate. A comparison between $(\mathrm{dT})_{20}$ and the corresponding mononucleotide (thymidine monophosphate, TMP) allows us to discuss the involvement of the triplet state in the dimer formation.

Our experiments were performed using the fourth harmonic (266 nm) of a Nd/YAG laser delivering $8 \mathrm{~ns}$ pulses at repetition rate of $2 \mathrm{~Hz}$. TMP and $(\mathrm{dT})_{20}$ were dissolved in phosphate buffer. The solutions were nitrogen purged. Measurements were carried out at room temperature. For both compounds, the optical density was adjusted to 0.24 (266nm, $1 \mathrm{~mm})$.

The transient spectra recorded for TMP solutions at $200 \mathrm{~ns}$ correspond to the well characterized TMP triplet, ${ }^{8-10}$ peaking at $360 \mathrm{~nm}$ (Figure 2a). The transient signals decay at all wavelengths $(280-600 \mathrm{~nm})$ with the same time constant of 5 $\mu$ s. The differential absorbance $(\Delta \mathrm{A})$ below $300 \mathrm{~nm}$ is negative because the molar extinction coefficient $(\varepsilon)$ of the triplet is smaller than that of the ground state. When the same experiment is performed with the oligonucleotide, no transient absorption is detected between $300 \mathrm{~nm}$ and $700 \mathrm{~nm}$ (Figure 2a). Taking into account the sensitivity of our set-up $\left(\Delta \mathrm{A}=2 \times 10^{-4}\right)$ we conclude that, at $200 \mathrm{~ns}$, the triplet concentration in the oligonucleotide solution is at least one order of magnitude lower than that of TMP. ${ }^{11}$

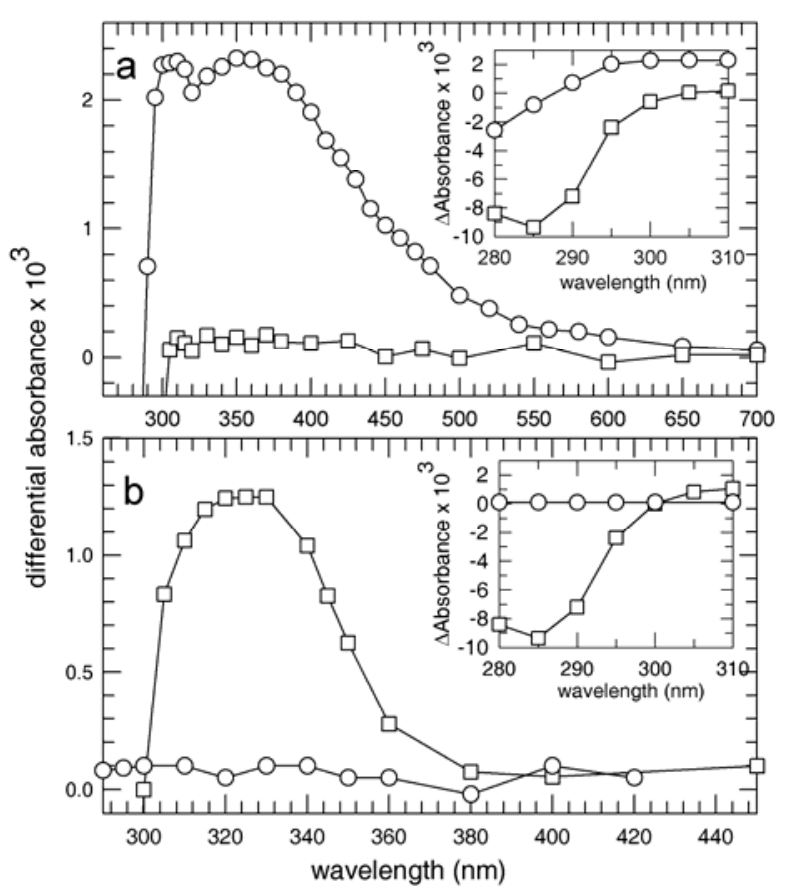

Figure 2. Transient absorption spectra recorded at $200 \mathrm{~ns}$ (a) and $10 \mathrm{~ms}$ for TMP (circles) and at (dT) 20 (squares). Excitation density at $266 \mathrm{~nm}$ : $1.2 \mathrm{MW} / \mathrm{cm}^{2}$.

In spite of the absence of any absorption band in the spectra recorded for $(\mathrm{dT})_{20}$ at the nanosecond and at the microsecond time-scales, a band peaking at $325 \mathrm{~nm}$, typical of the (6-4) adduct, ${ }^{4,12}$ does appear at the millisecond time-scale (Figure $2 \mathrm{~b}$ ). The transient signals recorded from $310 \mathrm{~nm}$ to $360 \mathrm{~nm}$ have the same time-behavior. The (6-4) transient absorption reaches its maximum value within $4 \mathrm{~ms}$ (Figure $3 \mathrm{a}$ ) and then it remains constant till, at least, $100 \mathrm{~ms}$. The same band is encountered in the steady-state absorption spectra of $(\mathrm{dT})_{20}$ solutions irradiated with $267 \mathrm{~nm}$ laser pulses ( $c f$ supporting information). Excitation at this band gives the fluorescence spectrum of (6-4) 
photoadduct $^{13}$ with a quantum yield of $(2.6 \pm 0.5) \times 10^{-2}$, in agreement with the literature value $\left(3 \times 10^{-2}\right){ }^{12}$

The delay with which the (6-4) absorption is observed proves that this adduct is formed via a reactive intermediate which absorbs below $300 \mathrm{~nm}$. The oxetane (Figure 1), predicted to be a precursor of the (6-4) adduct, ${ }^{5}$ is less conjugated than the (6-4) photoproduct and, therefore, is expected to absorb at lower wavelengths.

The signals obtained for $(\mathrm{dT})_{20}$ at the 280 - $310 \mathrm{~nm}$ range are negative and remain constant (Figure $2 b$ ) over the whole time domain probed (200 ns - $100 \mathrm{~ms}$ ). This shows the formation of stable photoproducts in less than 200 ns. Since the signal intensity at $290 \mathrm{~nm}$ is not affected by the transformation of oxetane to (6-4), the contribution of these two compounds should be negligible. Therefore, the signal at $290 \mathrm{~nm}$ is attributed to the ground state depletion induced by the formation of $\mathrm{T}<>\mathrm{T}$ dimers (four isomers).

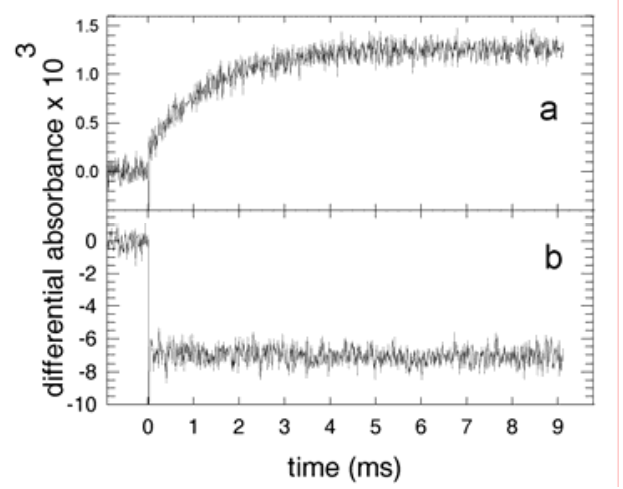

Figure 3 Transient signals obtained for $(\mathrm{dT})_{20}$ at $325 \mathrm{~nm}$ (a) and 290 $\mathrm{nm}$ (b). Excitation density at $266 \mathrm{~nm}: 1.2 \mathrm{MW} / \mathrm{cm}^{2}$. None of the signals is affected when oxygen is bubbled in the solution.

The concentrations of the TMP triplet as well as those of the dimers formed in the oligonucleotide vary linearly with the number of absorbed photons. Consequently, the corresponding quantum yields can be determined from the slopes of the linear regressions in Figure 4 . The intersystem crossing yield ( $\phi_{\text {ISC }}$ ) found for TMP is $(1.4 \pm 0.1) \times 10^{-2}$, in excellent agreement with that reported previously. ${ }^{8}$ The yields associated to $\mathrm{T}<>\mathrm{T}$ and (64) formation in (dT) $)_{20}$ are $(2.8 \pm 0.2) \times 10^{-2}$ and $(3.7 \pm 0.3) \times 10^{-3}$, respectively. The quantum yield determined for the (6-4) formation from the steady-state absorption spectra of laser irradiated solutions is $(3.5 \pm 0.4) \times 10^{-3}$, in agreement with that determined from the transient absorption measurements.

These values are 2-3 times higher than those derived from continuous irradiation of the dinucleoside TpT at $266 \mathrm{~nm}$ $\left(1.3 \times 10^{-2} \text { for } \mathrm{T}<>\mathrm{T} \text { and } 8 \times 10^{-4} \text { for (6-4) }\right)^{4}$. Such a difference can be explained by a lower dimerization probability in TpT as compared to $(\mathrm{dT})_{20}$ for which each thymine can react with either neighbor.

The absence of any triplet absorption from the transient spectra of $(\mathrm{dT})_{20}$ may be due to a decrease in $\phi_{\text {ISC }}$ upon oligomerization by at least one order of magnitude $\left(\phi_{\text {ISC }}<\right.$ $1.4 \times 10^{-3}$ ). Such a change could arise from interactions between singlet excited states, revealed by fluorescence polarization measurements. ${ }^{16}$ Another explanation is that the triplet state reacts in less than $200 \mathrm{~ns}$ with quasi unit efficiency to yield cyclobutane dimers, since $\mathrm{T}<>\mathrm{T}$ are known to be formed under triplet photosensitization conditions. ${ }^{1}$ The data presently available do not allow us to favor one of the above hypotheses.

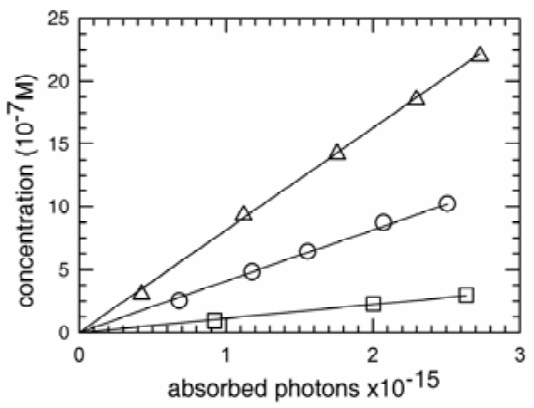

Figure 4. Concentrations of the photo-induced species as a function of the number of absorbed photons per pulse: TMP triplet at zero time (circles), $\mathrm{T}<>\mathrm{T}$ in (dT) $)_{20}$ (triangles) and (6-4) in (dT) $)_{20}$ (squares). The TMP triplet and (6-4) concentrations are determined for $\varepsilon_{\max }$ values of $2300 \mathrm{M}^{-1} \mathrm{~cm}^{-1},{ }^{10}$ and $4600 \mathrm{M}^{-1} \mathrm{~cm}^{-1},{ }^{14}$ respectively. The $\mathrm{T}<>\mathrm{T}$ concentrations are calculated considering that the formation of one dimer results to the depletion of two thymine residues and that the $\varepsilon$ of $(\mathrm{dT})_{20}$ at $290 \mathrm{~nm}$ is $1780 \mathrm{M}^{-1} \mathrm{~cm}^{-1}$ per base $\mathrm{e}^{15}$

In conclusion, this investigation constitutes the first insight regarding the time-scales at which the two major classes of pyrimidine dimers are formed. In particular, it brings experimental evidence that the (6-4) formation proceeds via a reaction intermediate. It opens new perspectives for the understanding of the dimerization mechanisms by examining the effect of biologically relevant factors, such as base sequence, base stacking or base pairing.

Acknowledgment. We thank the CNRS Chemistry Department for the specific funding attributed to this project, Ms Elodie Lazzarotto for her help and Dr Thierry Douki for fruitful discussions.

Supporting Information Available. Details on the experimental set-up, experimental procedure, determination of the quantum yields and steady-state spectra.

\section{References}

(1) Cadet, J.; Vigny, P. In Bioorganic Photochemistry; Morrison, H., Ed.; John Wiley \& Sons: New York, 1990, pp 1-272.

(2) Sihna, R. P.; Häder, D.-P. Photochemical \& Photobiological Sciences 2002, 1, 225-236.

(3) Wulff, D. L.; Fraenkel, G. Biochem. Biophys. Acta 1961, 51, 332-339; Varghese, A. J.; Wang, S. Y. Science 1967, 156, 955.

(4) Johns, H. E.; Pearson, M. L.; LeBlanc, J. C.; Helleiner, C. W. J. Mol. Biol. 1964, 9, 503-524.

(5) Varghese, A. J.; Wang, S. Y. Science 1968, 160, 186-187.

(6) Cadet, J.; Berger, M.; Douki, T.; Morin, B.; S., R.; Ravanat, J. L.; Spinelli, S. Biological Chemistry 1997, 378, 1275-1286.

(7) Nikogosyan, D. N. Int. J. Radiat. Biol. 1990, 57, 233-299; Görner, H. J. Photochem. Photobiol. B: Biol. 1994, 26, 117-139; Crespo-Fernàndez, C. E.; Arce, R. J. Phys. Chem. B 2003, 107, 1062-1070; Douki, T.; Angelov, D.; Cadet, J. J. Am. Chem. Soc. 2001, 123, 11360-11366.

(8) Salet, C.; Bensasson, R.; Becker, R. S. Photochem. Photobiol. 1979, 30, 325-329.

(9) Song, Q.-H.; Lin, W.; Yao, S.-D.; Lin, N.-Y. J. Photochem. Photobiol. A: Chem. 1998, 114, 181-184. 
(10) Gut, I. G.; Wood, P. D.; Redmond, R., W. J. Am. Chem. Soc. 1996, 118, 2366-2373.

(11) The assumption is made that the triplet absorption spectrum of thymine in (dT)20 is the same as for that of TMP.

(12) Blais, J.; Douki, T.; Vigny, P.; Cadet, J. Photochem. Photobiol. 1994, 59, 402-404.
(13) Franklin, W. A.; Lo, K. M.; Haseltine, W. A. J. Biol. Chem. 1982, 257, 13535-13543.

(14) Douki, T.; Zalizniak, T.; Cadet, J. Photochem. Photobiol. 1997, 66, 171179

(15) Riley, M.; Maling, B.; Chamberling, M. J. J. Mol. Biol. 1966, 20, 359389.

(16) Wilson, R. W.; Callis, P. R. J. Phys. Chem. 1976, 80, 2280-2288. 


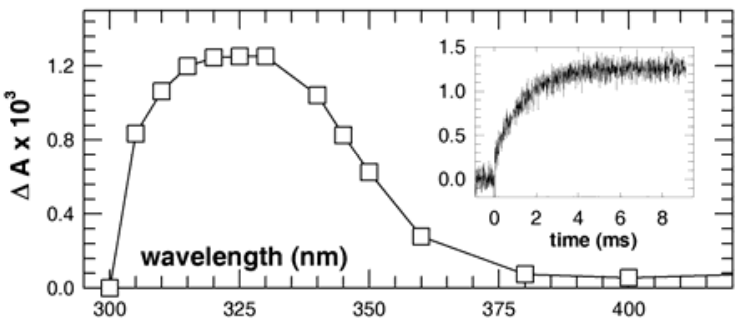

\section{ABSTRACT FOR WEB PUBLICATION}

The formation of thymine dimers in the single stranded oligonucleotide $(\mathrm{dT})_{20}$ is studied at room temperature by laser flash photolysis using $266 \mathrm{~nm}$ excitation. It is shown that the (6-4) adduct is formed within $4 \mathrm{~ms}$ via a reactive intermediate. The formation of cyclobutane dimers is faster than $200 \mathrm{~ns}$. The overall quantum yield for the (6-4) formation is (3.7 \pm 0.3$) \times 10^{-3}$ and that of the cyclobutane dimers $(2.8 \pm 0.2) \times 10^{-2}$. No triplet absorption is detected showing that either the intersystem crossing yield decreases by one order of magnitude upon oligomerization $\left(<1.4 \times 10^{-3}\right)$ or the triplet state reacts with unit efficiency in less than 200 ns to yield cyclobutane dimers. 